\title{
Unveiling assumptions through interdisciplinary scrutiny: Observations from the German Priority Program on Climate Engineering (SPP 1689)
}

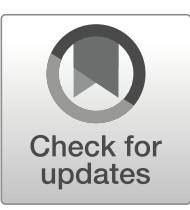

\author{
Judith Kreuter ${ }^{1}$ - Nils Matzner ${ }^{2,3} \cdot$ Christian Baatz $^{4}$ - David P. Keller ${ }^{5}$ - Till Markus ${ }^{6}$. \\ Felix Wittstock $^{6}$ - Ulrike Bernitt ${ }^{5} \cdot$ Nadine Mengis $^{5,7}$ (iD
}

Received: 28 October 2019 / Accepted: 25 June 2020 / Published online: 11 July 2020

(C) The Author(s) 2020

\begin{abstract}
The interdisciplinary exchange in climate engineering research offers a unique opportunity to make assumptions more explicit for such research projects. While making assumptions explicit is the standard in all disciplinary sciences, some assumptions in the context of societal challenges can only be usefully unveiled, discussed, and verified from the perspective of other research disciplines. Results from successful interdisciplinary collaborations are then more accessible and more generalizable to actors beyond the confines of the academic community. We aim to illustrate how interdisciplinary exchange helps to unveil assumptions in research endeavors and why this is important for successful interdisciplinary collaborations. We therefore follow different stages of the German Priority Program on Climate Engineering (SPP 1689), which we use as an example case of a successful interdisciplinary project. SPP 1689 focused on risks, challenges, and opportunities of Climate Engineering from the perspectives of numerous disciplines. Major results were that the initial assessments of technologies had to be sobered, the consideration of trade-offs is crucial for the potential assessment, and governance issues appeared larger than previously considered. From the reflections of SPP 1689, we conclude with three lessons learned: (1) The project profited from egalitarian organizational structures and communicative practices, preventing the predominance from single disciplines. (2) Within the project continuous efforts were undertaken to foster interdisciplinary understanding. In addition, the flexible project structure allowed for the accommodation of research needs arising as a result of these exchanges. (3) SPP 1689 offered early career researchers a platform for professional exchange on common challenges and best practices of being a part of an interdisciplinary research project.
\end{abstract}

Keywords Climate engineering $\cdot$ Interdisciplinarity $\cdot$ Assumptions $\cdot$ Communication $\cdot$ Carbon dioxide removal $\cdot$ Radiation management

Nadine Mengis

nmengis@geomar.de

Extended author information available on the last page of the article 
The need for interdisciplinary research to address societal challenges Climate engineering (CE) refers to large-scale technical approaches to deliberately intervene in the Earth's climate system to counteract the societal challenge of anthropogenic climate change (Shepherd and Working Group on Geoengineering the Climate 2009; Rickels et al. 2011). It is an umbrella term for two different kinds of approaches: Carbon dioxide removal (CDR) aims at reducing the main driver of anthropogenic climate change in the atmosphere. Radiation management (RM) methods aim at deliberately modifying the global radiation budget, thereby counteracting warming due to anthropogenic climate change. CE poses social, economic, political, technological, environmental, and ethical challenges. Because of the intricate complexity of the topic, an inherently interdisciplinary approach is needed to investigate the potential impacts and implications of $\mathrm{CE}$ in a comprehensive, rigorous, and reflective manner (see Rayner et al. 2013). "[S]ocial and natural processes are nowadays recognized as inextricably linked to one another and [...] neither of them can be fully appreciated without understanding the other" (Markus et al. 2018, 503).

We argue that interdisciplinary interaction facilitates to reveal, question, and sharpen necessary epistemic assumptions made by researchers from one discipline about the subject area of another discipline. And beyond that, this mutual understanding forms the basis for successful interdisciplinary work. In the context of this paper, assumptions are epistemic statements, ideas, or theories which are or have become accepted without further proof. The requirement to make assumptions in the context of scientific disciplines comes from the need to narrow the research question to an extent that the analysis can be conducted in a meaningful framework, and the results can still be interpreted. Assumptions can be implicit or explicit. While implicit assumptions can be unveiled, once assumptions are explicit, they can be reflected upon and questioned. By discipline, we mean a subsection of research delineated by "similar canons of rigour, a similar set of problems, and similar theoretical assumptions" (Boden 1999, 13). In other words, a discipline has its own areas of research (e.g., the climate system or society) and has to make assumptions about another's discipline area of research (e.g., about how society or individual actors will behave or how the climate will develop).

In the following, we outline examples from the Priority Program "Climate Engineering Risks, Challenges, Opportunities?" (SPP 1689) funded by the German Research Foundation (DFG) to argue our case. To do so, we describe steps taken within this project to set the foundation for successful interdisciplinary work. We then outline how interdisciplinary discourse helped to foster the process of unveiling discipline-specific assumptions and critical reflections thereof. As a result of these exercises, truly interdisciplinary collaboration was achieved. We will conclude with discussing challenges, factors of success, and lessons learned from SPP 1689. Note, that the SPP 1689 was not the only interdisciplinary research program on CE: The British projects Integrated Assessment of Geoengineering Proposals (IAGP, 2010-2015) and Stratospheric Particle Injection for Climate Engineering (SPICE, 20102014) and the European Transdisciplinary Assessment of Climate Engineering (EuTRACE, 2012-2014) worked interdisciplinarily, too. However, our reflections rely on the German SPP (2013-2019) as an umbrella for several individual projects, which were each interdisciplinary themselves. The involved disciplines included physics, chemistry, meteorology, biogeosciences, economy, law, philosophy, linguistics, sociology, and political science.

Interdisciplinary formation phase Early interdisciplinary approaches in the context of CE were a report by the British Royal Society (Shepherd and Working Group on Geoengineering the Climate 2009) and the Oxford Principles (Rayner et al. 2013). At the time, the German 
scientific community was mostly skeptical of the idea of CE. A publicly funded roundtable in 2008 gave room to discuss concerns about and possibilities for CE research (Oschlies and Klepper 2017). As a follow-up, a "series of interdisciplinary round table discussions gained momentum over subsequent meetings" (Oschlies and Klepper 2017, 129). Many of the participating researchers were involved in writing a scoping study (Rickels et al. 2011) commissioned by the German Federal Ministry of Research (BMBF). This study provided a timely and comprehensive review of scientific, economic, political, social, ethical, and legal aspects of CE. During this formation phase, it became clear that intensive interdisciplinary research was needed to determine risks, challenges, and opportunities of CE:

When in 2012 the German Research Foundation (DFG) debated if a large-scale program on risks and challenges of $\mathrm{CE}$ should be funded, the interdisciplinary character of the program proposal was key to the final decision. As agreed upon, interdisciplinarity was required to address complex problems associated with $\mathrm{CE}$, and that current international $\mathrm{CE}$ research lacked this integration of various disciplines under a common framework (NKGCF; SKO; SKZAG 2012, 7). SPP 1689 “Climate Engineering - Risks, Challenges Opportunities?” came into being as a decidedly interdisciplinary research endeavor aiming to comprehensively assess CE approaches (Oschlies and Klepper 2017). The program was to be made up of several projects. To be part of the program, project proposals had to make their interdisciplinary research agenda explicit. Thus, each project had an interdisciplinary core, a central question which could not be answered from one disciplinary perspective alone.

This phase, in which the principal investigators worked together to define these projects, laid the groundwork for the egalitarian structures and practices of SPP 1689. The cautious steering by the SPP 1689 coordination and the mutually respectful treatment of all disciplinary accounts helped to integrate various disciplines. However, during the 6 years of the project, continuous efforts had to be put forward by the project coordination to make it a successful interdisciplinary research endeavor.

Initial return to disciplines With the start of each of the projects under the program, additional researchers were introduced, many of which were at early career stages. This initiated a reorientation phase in which researchers within the subprojects started to assess problems through their respective disciplinary perspectives. They consulted their discipline's tools, such as specific methods for data generation and analysis and theoretical approaches to assess the subject matter. This step of returning to the disciplines is important for robust interdisciplinary research because it allows individual researchers to reflect on how they can contribute to the project. This preparatory work takes time and energy in itself. It is also at this stage that many assumptions with a disciplinary focus are being made. Since disciplinary research cannot investigate the whole spectrum of questions related to societal challenges, it is necessary to base the research on an array of assumptions about factors and variables lying outside of the individual researcher's scope:

For example, to assess environmental impacts and the effectiveness of $\mathrm{CE}$ measures in a computer model, we need to make assumptions about when and how society as a collective, rational, global actor would implement this measure. In an idealized study early in the SPP 1689, Keller et al. (2014) made the assumption that CE began at very high levels simultaneously all over the world in the year 2020 and that $\mathrm{CO}_{2}$ emissions at the same time remained high. While the authors knew that these assumptions were unrealistic, the study was nonetheless useful to investigate maximum CE potentials and impacts and started debates. It was only after presenting the results and discussing them with other members of SPP 1689 that the main 
author (D. Keller) was able to critically reflect on the details of these particular assumptions. These interdisciplinary exchanges helped to highlight that the study did not take into account internal heterogeneity of local, national, and global societies, and that if those were taken into account, the implementation of the CE measures in the study would be different.

Integration of interdisciplinarity on all levels The return to the known, disciplinary fields is important to set a rigorous groundwork for well-informed interdisciplinary exchange. However, efforts are required to ensure that this does not supersede interdisciplinary work and also to reintegrate the newly introduced researchers into the interdisciplinary research project. These efforts need to be put into the training of the researchers involved and the continual communication between the disciplines.

At the beginning of SPP 1689, iterative exchanges for young scientists were initiated which gave them opportunities to develop a shared understanding of disciplinary approaches. Workshops were held to provide this groundwork by exchanging knowledge on research methods and approaches in various disciplines included in the project:

- A modeling workshop addressed both climate and economic modeling approaches, to introduce researchers not familiar with such methods to the practice of setting parameters and the implications for model outcomes [January 2014, Hamburg, 29 participants].

- An interdisciplinary communication workshop was designed as a result of program-wide discussions about the meaning of terms used by many disciplines but with very different meanings, such as "uncertainty." This workshop raised awareness for the differences in vocabularies applied in disciplines and increased mutual understanding [July 2014, Kassel, 24 participants].

- A discourse analysis workshop aimed to foster understanding of tools in social sciences (assessing written or spoken text, imagery, or other media as part of the fabric of social reality, see, e.g., Böttcher 2019; Matzner and Barben 2020); at the same time, an argument analysis exercise informed attendees about the tools used in moral and political philosophy (identifying, reconstructing, and critically analyzing arguments for their logical validity and plausibility, see, e.g., Baatz 2016, Neuber 2018) [December 2014, Heidelberg, 17 participants].

Beyond these exchanges, early career researchers were supported through training of competencies relevant to careers in all disciplines, such as paper writing and presentation skills. In addition to these trainings, several dedicated joint $\mathrm{PhD}$ retreats were organized to allow for continuous exchange between the researchers.

All structures and opportunities described above are, in themselves, part and parcel of interdisciplinary research understood as "efforts to knowledge production that cross or bridge disciplinary boundaries" (Frodemann 2010). At the same time, they provide the basis from which to enhance interdisciplinary interaction further by making use of the understanding of the works of others to better understand the implications and context of one's own work.

Revealing underlying assumptions Assumptions underlying individual research endeavors to answer specific research questions are powerful precisely because they are not reflected further, thus taken as given. But crucially, assumptions often touch upon issues outside of a given discipline's subject matter. In such cases, it can be difficult from a disciplinary perspective to identify in what ways an assumption is contestable or what the associated 
uncertainties are. This is all the more relevant in research endeavors surrounding societal challenges such as climate change and $\mathrm{CE}$, which feeds into informing decision-making processes (see also Fisher et al. 2010; Ellenbeck and Lilliestam 2019). Implicit and explicit assumptions potentially veil implications of non-transparent, narrow assessments of complex societal challenges. In contrast, interdisciplinary research renders results more robust by unveiling, discussing, and verifying or replacing assumptions in due course. For example, under assumptions made within certain cost-benefit analyses, solar RM might be evaluated positively. However, if contested and adjusted, under a different set of assumptions, e.g., including considerations of political feasibility and justice, the technology might do more poorly (Bellamy et al. 2016, 282). Specific structures and approaches can prepare the grounds for such an exchange to take place:

Throughout SPP 1689, researchers presented their methods on six internal retreats to the interdisciplinary audience of the program. The conscious decision to have internal-only retreats fostered an atmosphere of mutual respect for critical but constructive exchanges. In addition to these internal retreats, in the context of the SPP 1689, an international conference was organized. Again with the goal to foster interdisciplinary exchange, this conference did not hold parallel sessions but remained in plenary throughout. Where the retreats and the conference assembled all SPP 1689 researchers, additional workshops served the purpose of discussing special topics. Nine thematic workshops with selected, invited, international experts were held in total.

Through presentations in these contexts, researchers from SPP 1689 opened their studies up for interdisciplinary scrutiny, where researchers in the audience were able to identify, comment, and question implicit and explicit assumptions. This exchange was key to allow for the unveiling of the potential contestability of the assumptions made. It provided the basis for researchers to critically reflect their own and other researchers' work and to identify previously made assumptions, some of which are, however, contestable or highly uncertain from another discipline's perspective. This mutual understanding, which evolved from these non-trivial exercises of presenting research results to an interdisciplinary audience, then was followed by a phase of identifying joint projects between participants from multiple disciplines.

These new questions as genuine products of interdisciplinary exchange between the project participants could be accommodated thanks to the flexible design of the DFG's priority programs. Members of the program then were able to suggest and realize thematic workshops to further discuss these new topics, which included metrics and indicators for CE assessment, $\mathrm{CE}$ in the context of the $1.5^{\circ} \mathrm{C}$ target, detection and attribution, liability and regulation, or responsible research and governance of $\mathrm{CE}$ :

At the workshop on "Integrative Approaches to Risk/Technology Assessment," participants developed four pathways representing different "possible alternative futures" (Böttcher et al. 2015,3 ) of decision-making on solar RM. In the course of this work, researchers from natural sciences, social sciences, law, and philosophy identified relevant assumptions underlying the Representative Concentration Pathways (RCPs) of the IPCC's Fifth Assessment Report (IPCC 2018). Whether, for example, international political cooperation to pursue the high mitigation scenario (RCP2.6) is considered feasible or not depends on specific assumptions. Individual state behavior and interests can be assumed to develop through international interaction or alternatively to be determined by the given situation of the respective state in the international system. The scenario workshop 'helped increase the participants' understanding of the complexity of the multi-faceted cause-effect relationships between extreme weather events and political decision-making" (Böttcher et al. 2015, 16). 
The aforementioned assumptions are particularly relevant when attempting to understand human behavior with respect to $\mathrm{CE}$ technologies. On the one hand, we could assume that an (collective) actor is deciding on CE implementation based on economically rational and wellinformed cost-benefit calculations. On the other hand, we could assume that issues of political feasibility, acceptability, and momentum might feed into such a development (Lederer and Kreuter 2018). The respective scenarios and corresponding modeling results are, to some degree, shaped by assumptions of such societal factors. Furthermore, social scientists will question the assumption that society can be considered a single collective actor and rather study the heterogeneity of society, the distribution of decision-making power, and the differentiation of choices that come with various climate outcomes.

Other examples are two workshops on metrics and indicators- "development of assessment metrics" and "metrics in the context of Climate Engineering"-which brought together climate modelers, economic modelers, social scientists, and moral philosophers to address the challenge of selecting appropriate indicators for the assessment of CE technologies. Interdisciplinary communication helped identify that ad hoc climate change indicators which are commonly used and assumed accurate for CE assessment probably introduce an assessment bias (Mengis et al. 2019). As a result of the workshops, an opinion piece outlined an ideally iterative approach between various disciplines and non-academic stakeholders to identify appropriate assessment indicators (Oschlies et al. 2017). Motivated by these discussions, several projects provided suggestions for the improvement of assessment metrics: Mengis et al. $(2018,2019)$ used an Earth system model to identify which relationships in the Earth system are disrupted by large-scale manipulation of the climate system. In parallel, a targetbased decision framework was developed for economic modeling that allows to calculate trade-off between climate policies costs and the "risk" of violating a climate target (Roshan et al. 2019). This approach now allows for the inclusion of a multitude of different Earth system variables. Matzner et al. are in the process of developing a social scientific approach to map the metrics used in current $\mathrm{CE}$ research to obtain an overview over the $\mathrm{CE}$ assessment landscape and to identify biases and research gaps.

Comprehensive interdisciplinary research While reducing complexity (e.g., within disciplinary research) is an important and necessary tool for research, an interdisciplinary approach is a fruitful exercise which allows researchers to make studies on complex societal challenges more comprehensive. On this basis, the robustness of assumptions going into the research process can be increased, and questionable assumptions in the design of studies can be avoided.

Recognizing the value of multi-model intercomparison projects and the lack of an equivalent to the Geoengineering Model Intercomparison Project (GeoMIP, which assesses the impact of RM measures on the Earth system), the Carbon Dioxide Removal Intercomparison Project (CDRMIP) was initiated through SPP 1689 (Keller et al. 2018). This project was initiated to help answer fundamental questions concerning the response of the Earth system to CDR. A prominent example of how the interdisciplinary dialogue influenced CDRMIP is that input from integrated assessment modelers (socioeconomic specialists), who had already been using CDR in climate change scenarios, guided the design of experiments as well as the experimental protocols (see Keller et al. 2018). More specifically, some CDRMIP experiments were designed to evaluate if socioeconomic modeling correctly accounted for CDR (see Rotmans and van Asselt 2001, for more information on integrated assessment models) and to provide information that can be used to derive improved parameters for these models. In CDRMIP, the value of interdisciplinary dialogues is recognized to such a degree that they will inform the design of all new experiments. The interdisciplinary dialogue 
also spurred further research efforts to identify modeling biases and misconceptions (Rickels et al. 2019).

The reflection process in the context of successful interdisciplinary research prevents two potential pitfalls of disciplinary studies: First, undue overconfidence in results which might not be applicable to situations outside of the specific scope of a study - both by the researchers themselves or by audiences which carry the information further, such as other researchers, decision-makers, or the public. This, in turn, can help avoid loss of confidence in scientific findings and subsequent relativism of knowledge claims. Second, such projects render results that are more accessible and more generalizable to actors beyond the confines of the academic community. Thus, the wider public and civil society groups can more easily engage meaningfully with the research and act as an "epistemic corrective" (Wehling 2012, 51) by bringing in their (real-world) knowledge and questions.

Challenges, factors of success, and lessons learned Reflecting on the course of SPP 1689, we identified a number of challenges and factors of success for the unveiling and reflection of assumptions through interdisciplinary interaction. Some key challenges and factors are highlighted in the following. They might be of value when designing future interdisciplinary research programs addressing societal challenges.

Firstly, SPP 1689 profited from egalitarian organizational structures and communicative practices: No discipline was understood as superior in answering relevant questions. Accordingly, all involved disciplines met as equal partners to jointly "work [...] on a single project" (Druckman et al. 2009, 503). For example, the roundtables were not held under the superior management or guidance from one specific discipline but provided the same access and voice to all disciplines involved. This provided the required time to jointly define research questions and identify ways ahead. Thus in SPP 1689, the definition of the central research problem was not left to some disciplines, while others were merely "allocated the task of filling the gaps within the given frame" (Szerszynski and Galarraga 2013, 2817). On the contrary, the egalitarian structure not only allowed for the struggle of hearing various perspectives on the subject matter but also the fruitful interaction of these perspectives.

Secondly, SPP 1689 highlighted the need for continuous efforts and actions for interdisciplinary understanding: The respective disciplinary training and backgrounds of the researchers involved provided them with the tools necessary to unpack issues of CE in depth. They are the prerequisite of integrated interdisciplinarity as "an enterprise in which some of the concepts and insights from one discipline contribute to the problems and theories of another - preferably in both directions." (Boden 1999, 20) However, such effort is required continuously to prevent a falling back to a disciplinary "comfort zone." Regular joint retreats that brought all researchers involved in the program together were the basis for these practices. In addition, at the beginning of SPP 1689 , preparatory workshops created a common basis of understanding and fostered interdisciplinary communication. Subsequent workshops on specific topics such as metrics and scenarios brought to light advantages of interdisciplinary exchange. This meant that in addition to engaging in disciplinary research activities the individual researcher also dove into previously unknown perspectives and approaches from other disciplines. Furthermore, researchers involved in such an endeavor have to undertake mindful and sustained efforts in interdisciplinary communication and goodwill to prevent misunderstanding.

Thirdly, SPP 1689 offered early career researchers a platform for professional exchanges as well as trainings on competencies relevant for all disciplinary career models. Beyond this, it offered a network for exchanges on common challenges and best practices of being a PhD 
candidate in an interdisciplinary research project. One of these challenges was that $\mathrm{PhDs}$ students as part of interdisciplinary projects commonly had to conform with disciplinary assessment criteria. Exchanges on this disciplinary/interdisciplinary split between early career researchers among themselves, and between individual early career researchers and senior researchers provided a first step towards bridging the split productively. This was an important step to ensure that disciplinary rigor did not overly restrict $\mathrm{PhD}$ candidates' leeway to engage in interdisciplinary work. The overall interdisciplinary exchange was strengthened by the substantial time investment of early career scientists into these exercises for which senior researchers would not have had the resources. Beyond that, these researchers will go on with a wider perspective on societal challenges but also for their future research endeavors, therefore profiting from this training throughout their future careers.

Designing and conducting research projects in accordance with these practices is timeconsuming and demands particular investments (Druckman et al. 2009, 504). These requirements have to be recognized not only by the individual researcher but also by research institutions and funding bodies. Such recognition can be shown, for example, by providing researchers with time required for their interdisciplinary work. Moreover, it should be reflected in amending criteria applied to assess performance quality, for instance regarding the number of publications expected in a given period. On a higher level, funding streams under national or regional research framework programs should not only assess proposals based on whether interdisciplinary interaction is built into the design but allow for and incentivize flexibility. This has proven to be a valuable trait in SPP 1689, because it allowed researchers to follow up on promising new insights gathered through interdisciplinary interactions that could not have been foreseen at the stage of the proposal design. Taking the necessary steps towards such improvement would indicate that the actors and institutions involved not only embrace the advantages of interdisciplinarity in theory but are also ready to walk the talk.

Funding Information Open Access funding provided by Projekt DEAL.

Open Access This article is licensed under a Creative Commons Attribution 4.0 International License, which permits use, sharing, adaptation, distribution and reproduction in any medium or format, as long as you give appropriate credit to the original author(s) and the source, provide a link to the Creative Commons licence, and indicate if changes were made. The images or other third party material in this article are included in the article's Creative Commons licence, unless indicated otherwise in a credit line to the material. If material is not included in the article's Creative Commons licence and your intended use is not permitted by statutory regulation or exceeds the permitted use, you will need to obtain permission directly from the copyright holder. To view a copy of this licence, visit http://creativecommons.org/licenses/by/4.0/.

\section{References}

Baatz C (2016) Can we have it both ways? On potential trade-offs between mitigation and solar radiation management. Environ Values 25(1):29-49

Bellamy R, Chilvers J, Vaughan NE (2016) Deliberative mapping of options for tackling climate change: citizens and specialists 'open up' appraisal of geoengineering. Public Underst Sci 25(3):269-286

Boden MA (1999) What is Interdisciplinarity? In: Cunningham R (ed) Interdisciplinarity and the organisation of knowledge in Europe. Office for Official Publications of the European Communities, Luxembourg, pp 1324

Böttcher M (2019) Cracking the code: how discursive structures shape climate engineering research governance. Environ Polit. https://doi.org/10.1080/09644016.2019.1670987 
Böttcher, M., Gabriel, J., Harnisch, S. (2015) Scenarios on stratospheric albedo modification deployment in 2030, SPP 1689 workshop report, Hamburg URL https:/www.spp-climate-engineering.de/Downloads_d. html?file=files/ce-projekt/media/download_PDFs/SSP1689_Workshop\%20Report scenarios.pdf

Druckman JN, Kuklinski JH, Sigelmann L (2009) The unmet potential of interdisciplinary research: political psychological approaches to voting and public opinion. Polit Behav 31:485-510

Ellenbeck S, Lilliestam J (2019) How modelers construct energy cost: discursive elements in energy system and integrated assessment models. Energy Res Soc Sci 47:69-77

Fisher E, Pascual P, Wagner W (2010) Understanding environmental models in their legal and regulatory context. J Environ Law 22(2):251-283

Frodemann, R. (2010): Introduction. In: Frodemann, R., Thompson Klein, J., Witcham, C., Holbrook, J. B. (eds.): The Oxford Handbook of Interdisciplinarity, 3-14

IPCC (2018) Summary for Policymakers. Global Warming of $1.5^{\circ} \mathrm{C}$. An IPCC Special Report on the impacts of global warming of $1.5^{\circ} \mathrm{C}$ above pre-industrial levels and related global greenhouse gas emission pathways, in the context of strengthening the global response to the threat of climate change, sustainable development, and efforts to eradicate poverty [Masson-Delmotte, V., P. Zhai, H.-O. Pörtner, D. Roberts, J. Skea, P.R. Shukla, A. Pirani, W. Moufouma-Okia, C. Péan, R. Pidcock, S. Connors, J.B.R. Matthews, Y. Chen, X. Zhou, M.I. Gomis, E. Lonnoy, T. Maycock, M. Tignor, and T. Waterfield (eds.)]. World Meteorological Organization, Geneva

Keller DP, Feng EY, Oschlies A (2014) Potential climate engineering effectiveness and side effects during a high carbon dioxide-emission scenario. Nat Commun 5:1-11. https://doi.org/10.1038/ncomms4304

Keller DP, Lenton A, Scott V, Vaughan NE, Bauer N, Ji D, Jones CD, Kravitz B, Muri H, Zickfeld K, The Carbon Dioxide Removal Model Intercomparison Project (CDR-MIP) (2018) Rationale and experimental protocol for CMIP6. Geosci Model Dev. https://doi.org/10.5194/gmd-2017-168

Lederer M, Kreuter J (2018) Organising the unthinkable in times of crises: will climate engineering become the weapon of last resort in the Anthropocene? Organization 25(4). https://doi.org/10.1177/1350508418759186

Markus T, Hillebrand H, Hornidge A-K, Krause G, Schlüter A (2018) Disciplinary research in marine sciences: the urgent case for an integration of research. ICES J Mar Sci 75(2):502-509

Matzner N, Barben D (2020) Climate engineering as a communication challenge: contested notions of responsibility across expert arenas of science and policy. Sci Commun 42(1):61-89. https://doi.org/10.1177 $/ 1075547019899408$

Mengis N, Keller DP, Oschlies A (2018) Systematic correlation matrix evaluation (SCoMaE) - a bottom-up, science-led approach to identify indicators. Earth Syst Dynam 9(1):15-31. https://doi.org/10.5194/esd-201772

Mengis N, Keller DP, Rickels W, Quaas M, Oschlies A (2019) Climate engineering-induced changes in correlations between Earth system variables - implications for appropriate indicator selection. Clim Chang. https://doi.org/10.1007/s10584-019-02389-7

Neuber F (2018) Buying time with climate engineering? An analysis of the buying time framing in favor of climate engineering. Ph.D. Thesis. Karlsruhe Institute of Technology (KIT), available at: https://publikationen.bibliothek.kit.edu/1000084294/16159169

NKGCF; SKO; SKZAG (2012): Climate engineering: Forschungsfragen einer gesellschaftlichen Herausforderung. Stellungnahme. Edited by Nationalen Komitee für Global Change Forschung (NKGCF), DFG Senatskommission für Ozeanographie (SKO), DFG Senatskommission Zukunftsaufgaben der Geowissenschaften (SKZAG). Bonn. Available online at http://www.dfg.de/download/pdf/dfg_im profil/reden_stellungnahmen/2012/stellungnahme_climate_engineering_120403.pdf, checked on 7/7/2019

Oschlies A, Klepper G (2017) Research for assessment, not deployment, of climate engineering: the German Research Foundation's Priority Program SPP 1689. Earth's Future 5(1):128-134. https://doi.org/10.1002 /2016EF000446

Oschlies A, Held H, Keller D, Keller K, Mengis N, Quaas M et al (2017) Indicators and metrics for the assessment of climate engineering. Earth's Future. https://doi.org/10.1002/2016EF000449/full

Rayner S, Heyward C, Kruger T, Pidgeon N, Redgwell C, Savulescu J (2013) The Oxford Principles. Clim Chang 121:499-512

Rickels W, Klepper G, Dovern J, Betz G, Brachatzek N, Cacean S, Güssow K, Heintzenberg J, Hiller S, Hoose C, Leisner T, Oschlies A, Platt U, Proelß A, Renn O, Schäfer S, Zürn M (2011) Gezielte Eingriffe in das Klima? Eine Bestandsaufnahme der Debatte zu Climate Engineering. BMBF, Berlin

Rickels W, Merk C, Reith F, Keller D, Oschlies A (2019) (Mis)conceptions about modelling of negative emissions technologies. Environ Res Lett, Online First. https://doi.org/10.1088/1748-9326/ab3ab4

Roshan E, Khabbazan MM, Held H (2019) Cost-risk trade-off of mitigation and solar geoengineering: considering regional disparities under probabilistic climate sensitivity. Environ Resour Econ:1-17. https://oi. org/10.1007/s10640-018-0261-9 
Rotmans J, van Asselt MB (2001) Uncertainty in integrated assessment modelling: a labyrinthic path. Integr Assess 2(2):43-55

Shepherd JG, Working Group on Geoengineering the Climate (2009) Geoengineering the climate: science, governance and uncertainty. Royal Society

Szerszynski B, Galarraga M (2013) Geoengineering knowledge: interdisciplinarity and the shaping of climate engineering research. Environ Plan A 45:2817-2824

Wehling P (2012) From invited to uninvited participation (and back?): rethinking civil society engagement in technology assessment and development. Poiesis Prax 9(1):43-60. https://doi.org/10.1007/s10202-0120125-2

Publisher's note Springer Nature remains neutral with regard to jurisdictional claims in published maps and institutional affiliations.

\section{Affiliations}

\section{Judith Kreuter ${ }^{1} \cdot$ Nils Matzner ${ }^{2,3} \cdot$ Christian Baatz $^{4}$ - David P. Keller ${ }^{5}$. Till Markus ${ }^{6}$.} Felix Wittstock $^{6}$ - Ulrike Bernitt ${ }^{5} \cdot$ Nadine Mengis $^{5,7}$

1 Political Science Institute, Technische Universität Darmstadt, Darmstadt, Germany

2 Munich Center for Technology in Society, Technical University of Munich, Munich, Germany

3 Department for Science and Technology Studies, Klagenfurt University, Klagenfurt, Austria

4 Philosophisches Seminar, Christian-Albrechts-Universität zu Kiel, Kiel, Germany

5 Research Unit Biogeochemical Modelling, GEOMAR Helmholtz Centre for Ocean Research Kiel, Kiel, Germany

6 Research Unit Environment and Society, Helmholtz Centre for Environmental Research, Leipzig, Germany

7 Geography Department, Simon Fraser University, Burnaby, BC, Canada 